\title{
Macular Corneal Dystrophy in Iceland
}

\author{
F. JONASSON, ${ }^{1}$ J. H. JOHANNSSON,${ }^{2}$ A. GARNER,${ }^{3}$ N. S. C. RICE ${ }^{4}$ \\ Reykjavik and London
}

\begin{abstract}
Summary
This study includes the fourteen Icelanders who had penetrating keratoplasty for macular corneal dystrophy during 1974 through 1988 , and a further five patients whose deterioration of vision has so far not led to surgery. The clinical presentation, mode of inheritance and the course of the disease were similar to those seen in other studies. The genealogical part of this study indicates that the gene responsible for the disease was already present in Iceland in the 18th century. Though consanguinity, as usually defined, was found to be uncommon, the relatively small pool of genes in the Icelandic population which numbers at present about 250,000 has led to higher prevalence of macular corneal dystrophy than elsewhere. The histopathological findings concur with the conventional description of macular corneal dystrophy, with the exception of two patients with unusually severe photophobia. In these two cases, electron microscopy revealed that the most anteriorly situated deposits were sometimes associated with increased electron-density of small clusters of basal epithelial cells in the overlying epithelium, such cells also being reduced in size and exhibiting few organelles other than swollen mitochondria.
\end{abstract}

Corneal dystrophies are inherited as autosomal dominant traits with the exception of macular corneal dystrophy and isolated instances of congenital heriditary endothelial and posterior polymorphous dystrophies. They primarily affect one layer of the cornea except macular corneal dystrophy where there is stromal as well as endothelial involvement. ${ }^{1}$ This dystrophy was first recognised in 1890 by Groenouw ${ }^{2}$ and in 1938 transmission as an autosomal recessive trait was demonstrated by Bücklers. ${ }^{3}$ Consequently both parents of affected individuals would be expected to be carriers of the gene.

When vision has deteriorated so as to affect normal activities keratoplasty is the treatment of choice. Lamellar keratoplasty should be avoided in macular corneal dystrophy because this dystrophy extends through the full thickness of the cornea. ${ }^{4}$ Macular corneal dystrophy may also recur within grafts after penetrating keratoplasty. ${ }^{5}$

Macular corneal dystrophy may be caused by failure to synthesise normal mature keratan sulphate proteoglycan or there may be a defect in catabolism. ${ }^{6,7}$ The results of a recent investigation ${ }^{8}$ suggest that macular corneal dystrophy may manifest heterogeneity with at least two varieties i.e. keratan sulfate negative (type I) and keratan sulfate positive (type II).

From: ${ }^{1}$ University Department of Ophthalmology, Landakot Hospital, Reykjavik, Iceland. ${ }^{2}$ Department of Pathology, University of Iceland, Reykjavik, Iceland. ${ }^{3}$ Institute of Ophthalmology, London. ${ }^{4}$ Moorfields Eye Hospital, London.

Presented at the Scottish Ophthalmological Club meeting, Edinburgh, October 1988.

Correspondence to: F. Jonasson, University Department of Ophthalmology, Landakot Hospital, 101 Reykjavik, Iceland. 


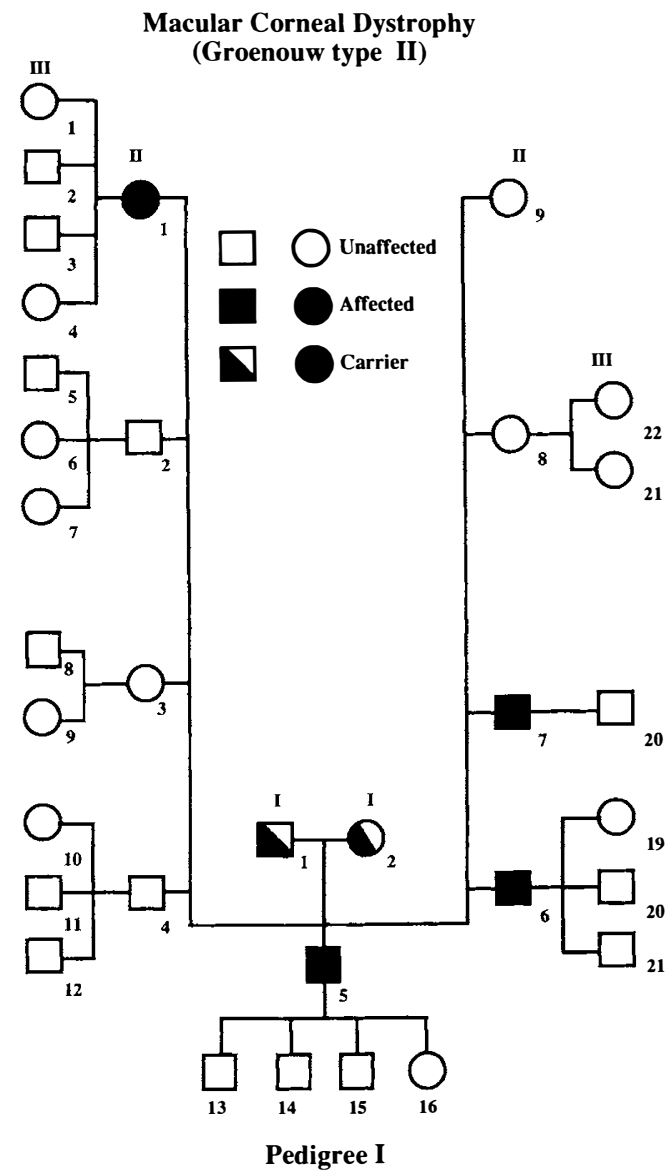

Fig. 1. Pedigree I: this pedigree may be considered classical for autosomal recessive inheritance.

\section{Material, Methods and Results}

Clinical observations: Our study includes the fourteen Icelanders, who had penetrating keratoplasty for macular corneal dystrophy during 1974-88 and a further five patients whose deterioration of vision has so far not led to surgery. In all instances both eyes were affected. The dystrophy in our 19 patients was detected at ages ranging from 3-25 years but in most instances the patients were in their teens. The vision had begun to deteriorate between the age of 15-25 years progressing to poor vision at the age of 19-35 years. Clinically the corneae were characterised by non-vascularised, poorly demarcated, graywhite, irregular opacifications within a diffusedly clouded stroma. The opacities were more dense in the axial region where they were first seen, though the entire cornea was involved later with some spots extending to the limbus. The opacities enlarged with time and did coalesce in some instances. The central denser macular opacities were found in the anterior stroma some even subepithelial, leading to irregular corneal surface and thus inducing irregular astigmatism. These superficial opacities also lead to photophobia and irritation.

The four patients in family one (Fig. 1) have had penetrating keratoplasty in both eyes and the diagnosis has been confirmed by light microscopy in all instances and electron microscopy in two instances. Two of them had severe problems with photophobia and sensation of corneal foreign body before and after

\section{Macular Corneal Dystrophy (Groenouw type II)}

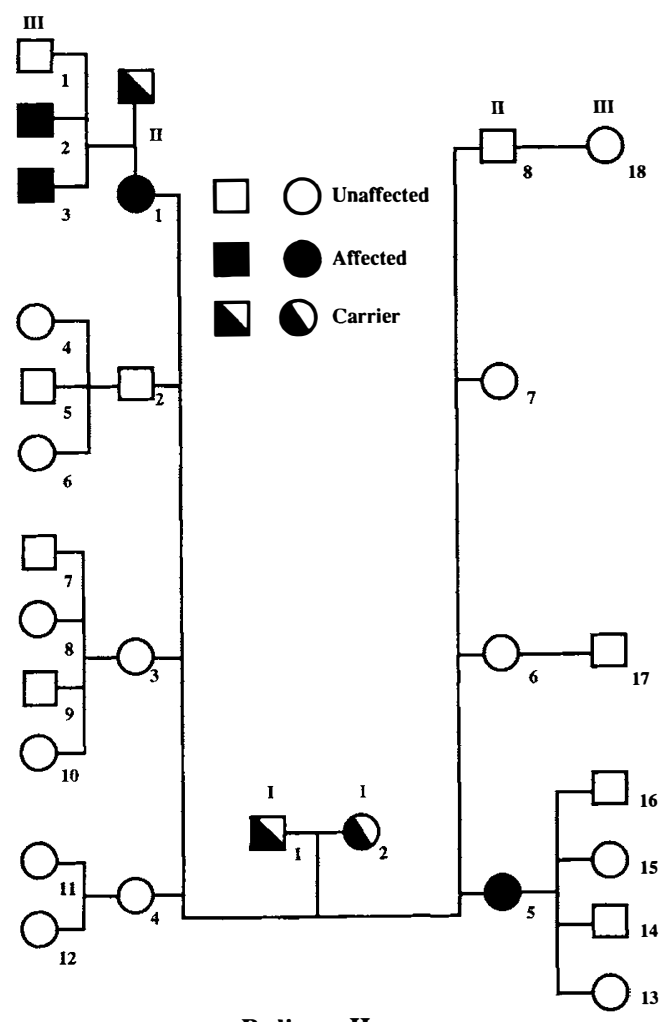

Pedigree II

Fig. 2. Pedigree II: the pseudodominance in this pedigree may reflect the high carrier frequency in the Icelandic population. 


\section{Macular Corneal Dystrophy (Groenouw type II)}

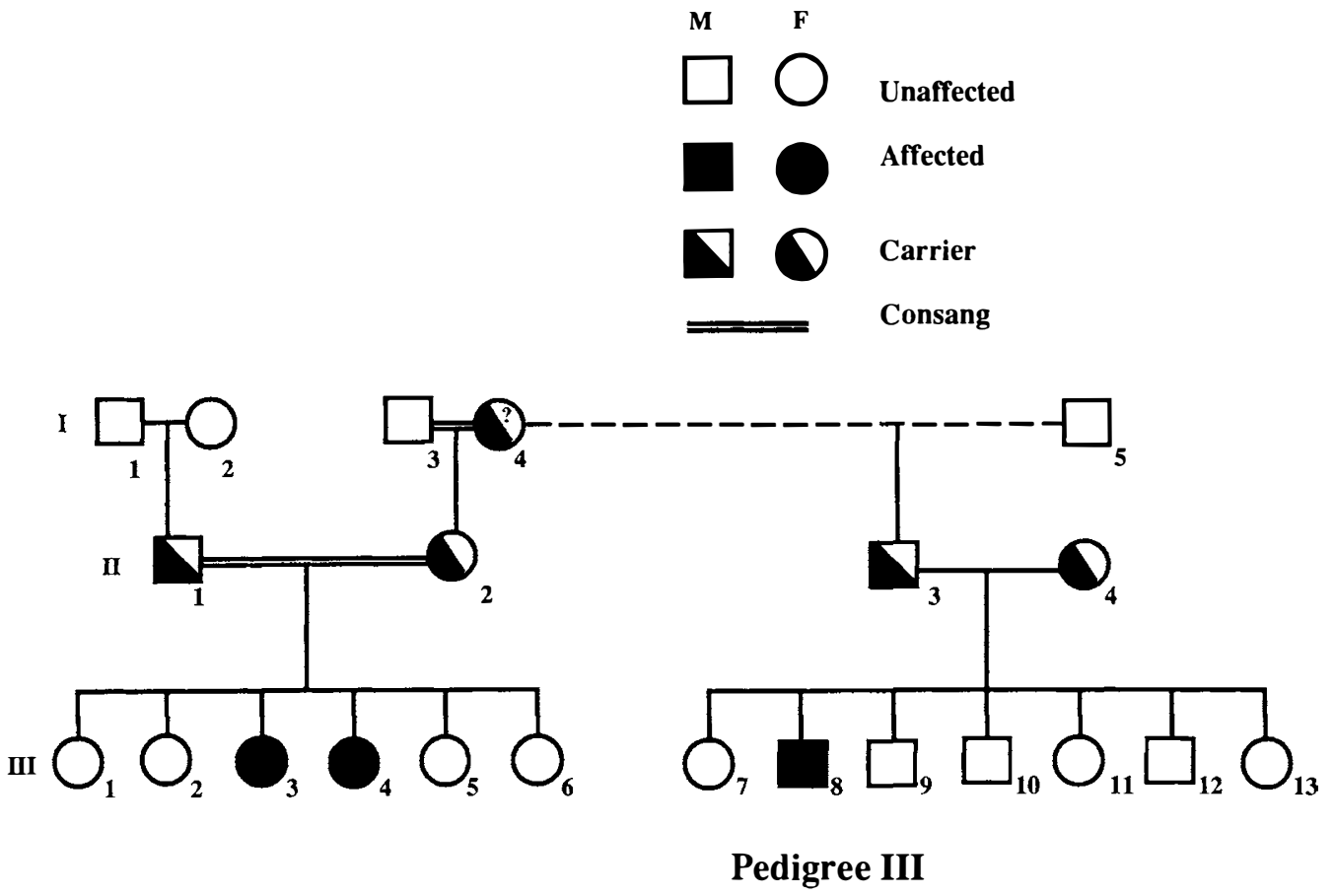

Fig. 3. Pedigree III: this was the only family where intermarriages were found.

keratoplasty and it is noteworthy that they were not improved by the use of a bandage contact lens either prior to or after keratoplasty. The two youngest sisters in this family complained of photophobia and recurrent foreign body sensation during their teens but the only abnormality found was "roughness" of the corneal epithelium and their symptoms diminished after the age of twenty.

Epidemiology, Genealogy and Inheritance: Our 19 patients from eleven families may be divided into three categories. First, eight patients, who were the only individuals affected in their families with no family history and no evidence of consanguinity.

Secondly, eight patients from two families where several members were affected (Figs. 1 and 2), in one of them through two generations (pseudodominance). In these families there was no previous history of the disease. A genealogist traced these families eight genera- tions back from the parents of the affected individuals to exclude consanguinity.

Thirdly, three patients, two sisters and their male first cousin (Fig. 3), and in this last family intermarriages were common.

The fact that the common ancestors of the parents of persons with macular corneal dystrophy were not found until in the 18 th century, together with the available information of the geographical whereabouts of the families for more than two centuries may permit us to assume that heterozygous carriers for macular corneal dystrophy were present in Iceland early in the 18th century.

Treatment: Fourteen patients, 26 eyes, have had penetrating keratoplasy (PK), which amounts to 30.2 per cent of all PKs during the 15 year period of study (Table).

The patients age in years when PK was first performed was 21-86 years, mean 37 , mode 32 years. The patient who was 86 years old 
Table I Indications for penetrating keratoplasty in Iceland 1974-88

\begin{tabular}{lrr}
\hline & No. eyes & Per cent \\
\hline Macular corneal dystrophy & 26 & 30.2 \\
Granular corneal dystrophy & 1 & 1.2 \\
Bowman layers dystrophies & 2 & 2.3 \\
Keratoconus/-globus & 8 & 9.3 \\
Fuchs endothelial & & \\
dystrophy & 6 & 7.0 \\
ABK and PBK & 7 & 8.1 \\
Herpes simplex & 9 & 10.5 \\
Regraft & 8 & 9.3 \\
Caustic burn & 1 & 1.2 \\
Trauma & 4 & 4.6 \\
Corneal scar & 7 & 8.1 \\
Interstitial keratitis & 2 & 2.3 \\
Keratitis profunda & 1 & 1.2 \\
Perforation from RA & 2 & 2.3 \\
Corneal abcess & 1 & 1.2 \\
ICE syndrome & 1 & 1.2 \\
Total: & 86 & 100.00 \\
\hline
\end{tabular}

when PK was first done, lived in a remote area and had had superficial corneal scraping several times through his life with some temporary improvement in vision. Other stromal dystrophies requiring $\mathrm{PK}$ are rare in Iceland (Table I). Five eyes out of the 26 have had a regraft, one of them had the initial graft five years after having sustained penetrating ocular trauma with iris adhesions. This eye was regrafted 14 years later because of endothelial failure, the other eye of the same patient had to be regrafted six years after the initial procedure because of endothelial decompensation. Of the remaining three eyes two were regrafted three and four years respectively after the initial procedure, both having had episodes of rejection and later endothelial decompensation, and in the third eye the decompensation followed cataract removal in a 72 year old lady. The fifth eye never cleared after the initial procedure, probably due to poor donor material, and was regrafted 18 years later. These five regrafts have remained clear with follow up from 1-9 years, though an episode of rejection recurred in one eye. None of the removed donor discs showed evidence of recurrence of the disease, either clinically or on light microscopy. No lamellar grafts were done.

Histopathology: Twenty of the 26 corneal but- tons removed at the time of penetrating keratoplasty were examined by light microscopy. Sections of paraffin-embedded tissue were stained with haematoxylin and eosin and with alcian blue, colloidal iron and the periodic acid-Schiff sequence for the histochemical identification of glycosaminoglycans ${ }^{9}$ (Fig. 4). In 13 cases we also stained histological sections using Grocott's methenamine-silver technique, which was found to be an excellent method for visualising the intra- and extracellular deposits. ${ }^{10}$ The stromal deposits of finely granular, amorphous material demonstrated in this way gave negative reactions to the Masson trichrome and congo red stains. Aggregates of glycosaminoglycans were observed in keratocytes and in the extracellular stroma, particularly anteriorly beneath a Bowman's layer that was commonly thinned, eroded or split above and around the heavier deposits. Endothelial cells contained similar fine granules in their cytoplasm, although Descemet's membrane was free of deposits. Descemet's membrane was, however, frequently thickened and showed focal posterior excrescences. The corneal epithelium was of uneven thickness in every case, especially in relation to the most superficial deposits where it was often attenuated, with focal clusters of degenerate cells (Fig. 5). Rarely, alcianophilic deposits were observed within the epithelium in relation to areas having a defective Bowman's layer.

Transmission electron microscopy was performed in respect of two patients, both brothers from Pedigree I who had exceptionally pronounced photophobia (Figs. 6 and 7). In each case packets of flocculent fibrillogranular material were identified within the cytoplasm of stromal keratocytes, some of which presented degenerative changes in the form of condensed cytosol and myelin figures, and in extracellular locations. The most anteriorly situated deposits were sometimes associated with splitting, erosion and dehiscence of Bowman's layer and with increased electron-density of small clusters of cells in the overlying epithelium, such cells also being reduced in size and exhibiting few organelles other than swollen mitochondria with absent cristae. 


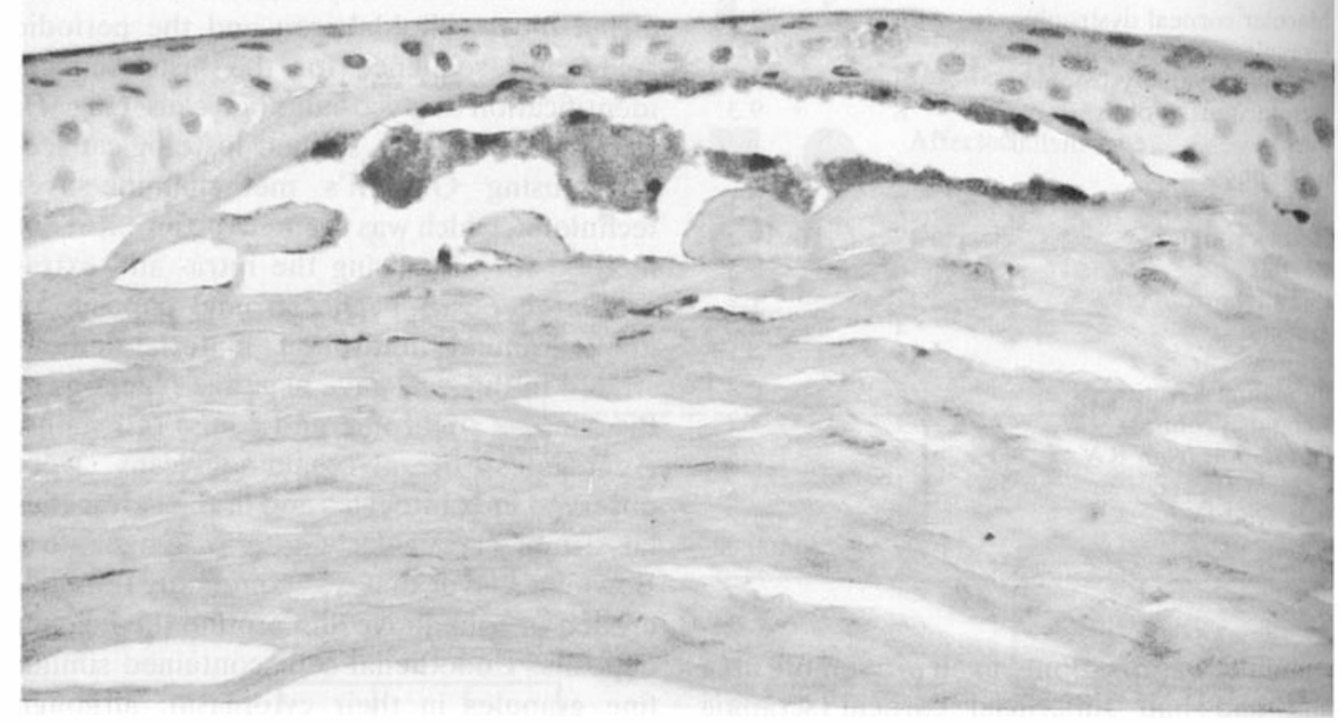

Fig. 4. An accumulation of finely granular alcianophilic material in the anterior stroma is associated with attenuation of the epithelium and erosion of Bowman's layer. (Alcian blue, X450).

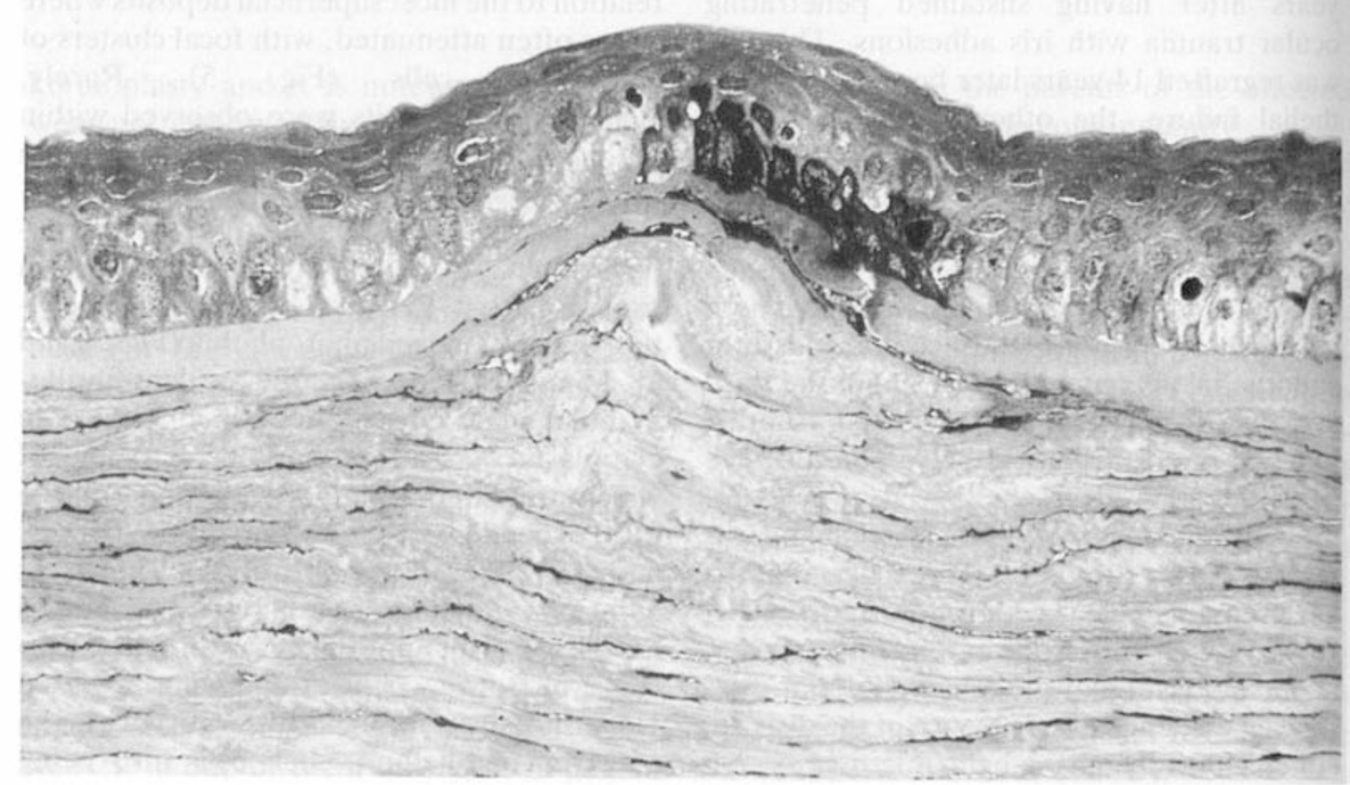

Fig. 5. Section of araldite-embedded tissue showing splitting and dehiscence of Bowman's layer and focal epithelial degeneration in association with glycosaminoglycan accumulation in the anterior stroma. (Toluidine blue, X450). 


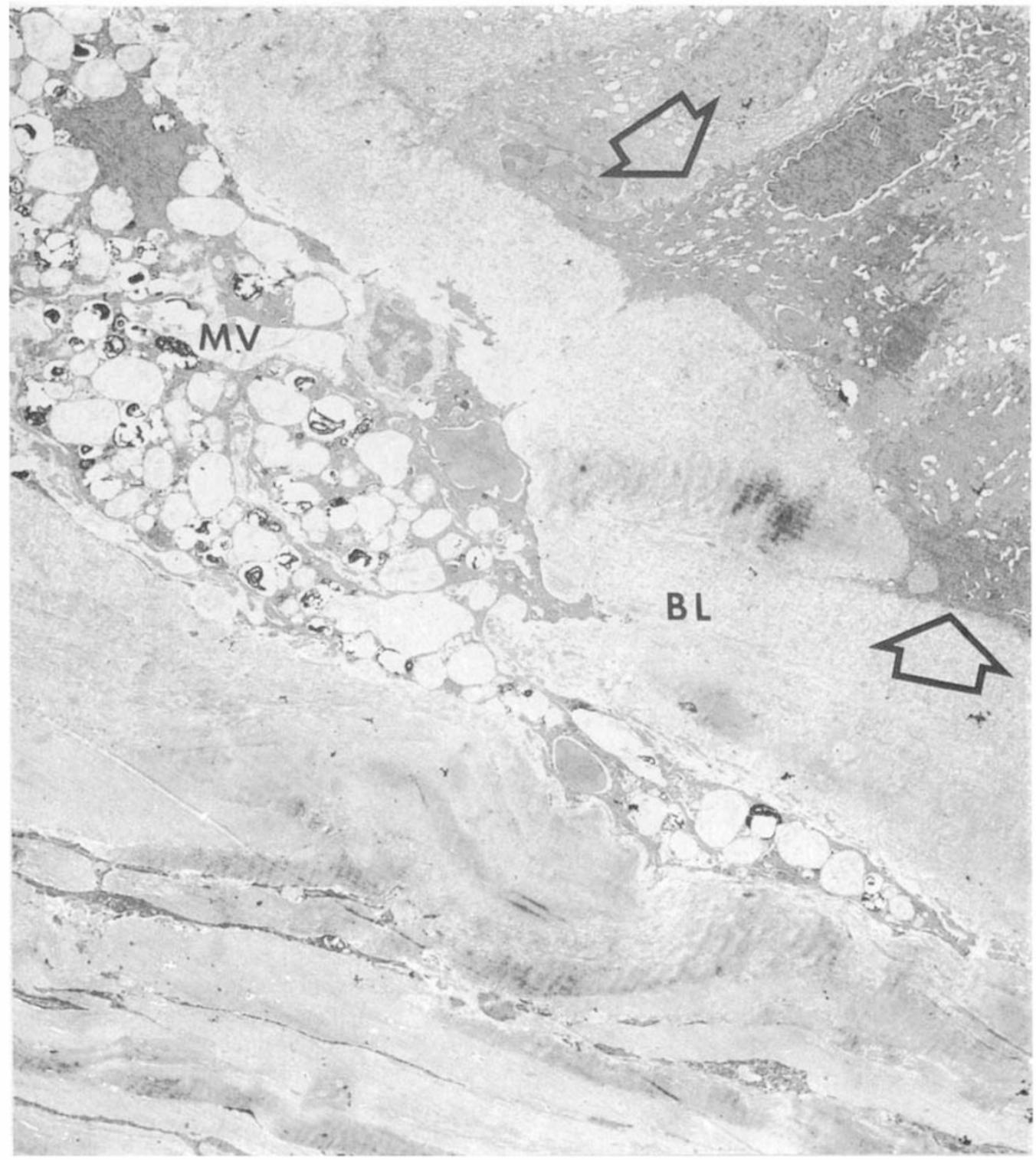

Fig. 6. Electron micrograph showing membrane vesicles (MV) filled with fibrillo-granular material identified histochemically as glycosaminoglycan and cellular debris beneath an eroded Bowman's layer (BL). Some of the overlying epithelial cells (arrows) are abnormally electron-dense with shrunken nuclei and vacuolation attributable to mitochondrial swelling. (Glutaraldehyde/araldite/uranyl acetatellead citrate, X3000).

\section{Discussion}

The prevalence of inherited diseases varies in different communities. This also applies to recessive conditions like macular corneal dystrophy, which may occur fairly frequently because of high frequency of the gene in the population under consideration. The eight isolated cases in our study are in keeping with autosomal recessive inheritance. Regarding the three families where several members are affected, Pedigree I may be considered to be a classical case of autosomal recessive inheritance. In Pedigree II there is pseudodominance present and this is probably related to 


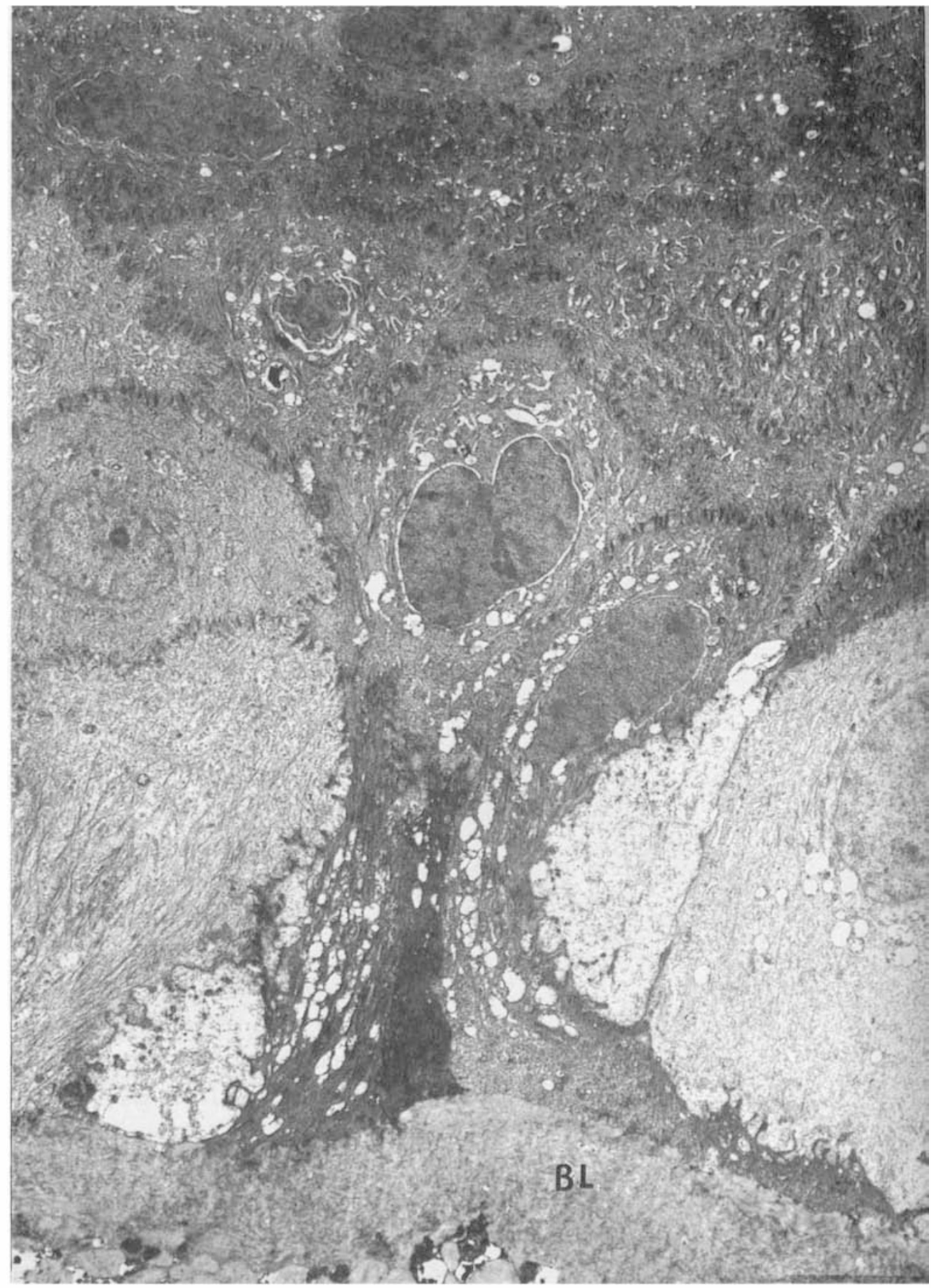

Fig. 7. Electron micrograph showing degenerate, electron-dense epithelium bounded by relatively normal cells and overlying an attenuated Bowman's layer $(B L)$ with subjacent glycosaminoglycan. (Glutaraldehyde/araldite) uranyl acetate/lead citrate, X4000). 
high frequency of carriers in the Icelandic population. In Pedigree III consanguinity is present. The population of Iceland is at present about 250,000 and it's pool of genes is consequently relatively small. The geneological part of this study indicates that the gene responsible for MCD was present in Iceland early in the 18th century.

Klintworth ${ }^{11}$ has maintained a registry of persons with macular corneal dystrophy in the United States for 20 years. His registry contains pedigrees, ancestral migratory patterns and other information on about 200 affected individuals from more than 100 families with this condition. This corresponds to 0.3 individuals per 250,000 inhabitants, the same figure for Denmark is $0.5^{12}$ and 19 for Iceland. Another indication for high prevalence of macular corneal dystrophy in Iceland is the fact that about every third corneal graft performed on Icelanders during the 15 year period of study was done because of macular corneal dystrophy. In comparison, studies from other countries have demonstrated all non-Fuch's corneal dystrophies combined to be the indication for $\mathrm{PK}$ in 3.4 per cent of instances in Los Angeles, ${ }^{13}$ about 4 per cent in Ann Arbor, ${ }^{14}$ and 6.7 per cent in Copenhagen. ${ }^{15}$ The average number of operations 1974-1988 was 5.7 PKs per year whereby there was an increase by more than one third during the second half of the study compared with the first half. Estimated yearly number of PKs performed in the USA, calculated for 250,000 inhabitants is 12.5 , and the same figure for the United Kingdom is 6.3.16

The histopathological findings in all cases, whether examined at light or electron microscope levels, concur with the conventional descriptions of macular corneal dystrophy. ${ }^{17.18 .19 .9 .20}$ Guttate excrescences and more generalised thickening of Descemet's membrane, as seen in several of the present cases, are also recognised features,,$^{21}$ and, while this aspect of the cornea was not studied in the present series, apparent impregnation of the membrane with glycosaminoglycans has been disclosed by ultrastructural investigation..$^{21,22}$ Of particular interest, however, are the epithelial changes noted in the two cases examined by electron microscopy, especially as both patients complained of unusually severe photophobia. Epithelial defects, other than variations in thickness, have not been a conspicuous feature of previously reported cases and it is tempting to suggest that this finding is related to the intense photophobia. As to the cause of the focal epithelial degeneration there is some difficulty in trying to ascribe this to breaks in the underlying Bowman's layer, since whereas defects at this level are frequent identifiable epithelial degeneration is rare. It may be, however, that the discrepancy is more apparent than real, given that the changes seen in the present cases were recognised only in toluidine blue stained araldite sections and by electron microscopy and were not seen in conventional paraffin-embedded sections. Whether the relationship, if real, between epithelial degeneration and deficiencies in Bowman's layer is mediated by contact with the stromal glycosaminoglycan or lytic substances elaborated by the dystrophic keratocytes is open to question.

This work was supported by the Landakot Hospital Research Fund.

\section{References}

${ }^{1}$ Waring GO, Rodrigues MM, Laibson PR: Corneal Dystrophies. I. Dystrophies of the Epithelium, Bowman's Layer and Stroma. Surv Ophthalmol 1978, 23: 71-120.

${ }^{2}$ Groenouw A: Knötchenförmige Hornhauttrübungen. Arch Augenheilkd 1980, 21: 281-9.

${ }^{3}$ Bücklers M: Die Erblichen Hornhautdystrophien: Dystrophiae corneae hereditariae. Bücherei des Augenarztes, (F. Enke, Stuttgart) Klin Monatsbl Augenheilkd 1938, suppl 3: 60-101.

${ }^{4}$ Robin AL, Richard Green W, Lapsa TP, Hoover RE, Kelly JS: Recurrence of macular corneal dystrophy after lamellar keratoplasty. $A m J$ Ophthamol 1977, 84: 457-61.

${ }^{5}$ Klintworth GK, Reed J, Stainer GA, Binder P: Recurrence of macular corneal dystrophy within grafts. Am J Ophthalmol 1983, 95: 60-72.

${ }^{6}$ Hassel JR, Newsome DA, Krachmer JH, Rodrigues M: Macular corneal dystrophy: failure to synthesize mature keratan sulphate proteoglycan. Proc Natl Sci USA 1980, 77: 3705-9.

${ }^{7}$ Bruner WE, Dejak TR, Grossniklaus HE, Stark WJ, Young E: Corneal alpha-galactosidase deficiency in macular corneal dystrophy. Ophthalmol Pediaet Genet 1985, 5: 179-83.

8 Yang JC, SundarRaj N, Thonar EJMA, Klintworth GK: Immunohistochemical evidence of heterogeneity in macular corneal dystrophy. $A m \mathrm{~J}$ Ophthamol 1988, 106: 65-71.

${ }^{9}$ Garner A: Histochemistry of corneal macular dystrophy. Invest Ophthalmol 1969, 8: 475-83. 
${ }^{10}$ Johannsson JH, Jonasson F: Methenamine-Silver staining in Macular Corneal Dystrophy. Am J Ophthalmol 1988, 106: 630-1.

${ }^{11}$ Klintworth GK: Macular corneal dystrophy-a localised disorder of mucopolysaccharide metabolism? In Donna L Daentl ed. "Clinical, Structural and Biochemical Advances in Hereditary Eye Disorders", New York, Alan R. Liss Inc., 1982, 69-101.

${ }^{12}$ Möller HU: Personal communication. 1988.

${ }^{13}$ Robin JB, Gindi JJ, Koh K, Schanzlin DJ, Narsing RA, York KK, Smith RE: An update of the indications for penetrating keratoplasty. Arch Ophthalmol 1986, 104: 87-9.

${ }^{14}$ Hidemann GG, Sugar A, Meyer RF, Musch DC: Oversized donor grafts in penetrating keratoplasty. Arch Ophthalmol 1985, 103: 1807-11.

${ }^{15}$ Baun O, Gregersen E, Prause JU: Irreversible immune reactions following keratoplasty. Acta Ophthalmol (Copenh) 1987, 65: 641-7.

${ }^{16}$ Casey TA, Mayer DJ: Corneal Grafting. WB Saunders Company 1984, 84.

${ }_{17}$ Jones ST and Zimmerman LE: Macular dystrophy of the cornea (Groenouw type II), clinicopathologic report of two cases with comments concerning its differential diagnosis from lattice dystrophy (Biber-Dimmer-Haab). Am J Ophthalmol 1959, 47: 1-16.

${ }^{18}$ Klintworth GK and Vogel FS: Macular corneal dystrophy: an inherited acid mucopolysaccharide storage disease of the corneal fibroblast. Am J Pathol 1964, 45: 565-86.

${ }^{19}$ Morgan G: Macular dystrophy of the cornea. $\mathrm{Br} \mathrm{J}$ Ophthalmol 1966, 50: 57-67.

${ }^{20}$ Tremblay $\mathbf{M}$ and Dube I: Macular dystrophy of the cornea: ultrastructure of two cases. Can J Ophthalmol 1973, 8: 47-53.

${ }^{21}$ Snip RC, Kenyon KR, Green WR: Macular corneal dystrophy: ultrastructural pathology of corneal endothelium and Descemet's membrane. Invest Ophthalmol 1973, 12: 88-97.

22 Klintworth GK: Disorders of glycosaminoglycans (mucopolysaccharides) and proteoglycans. In Garner A, Klintworth GK eds. Pathobiology of ocular disease: a dynamic approach. New York: Marcel Dekker 1982, 863-895. 